\title{
Strontium ranelate reduces the progression of titanium particle-induced osteolysis by increasing the ratio of osteoprotegerin to receptor activator of nuclear factor-кB ligand in vivo
}

\author{
TIANXIANG GENG ${ }^{1}$, SHOUXUAN SUN $^{2}$, XI CHEN $^{1}$, BOLUN WANG $^{1}$, \\ HAOHUI GUO ${ }^{2}$, SHUAI ZHANG ${ }^{2}$ and QUNHUA JIN ${ }^{2}$ \\ ${ }^{1}$ Department of Orthopedic Surgery, Ningxia Medical University; ${ }^{2}$ Department of Orthopedic Surgery, \\ General Hospital of Ningxia Medical University, Yinchuan, Ningxia 750004, P.R. China
}

Received June 22, 2017; Accepted November 2, 2017

DOI: $10.3892 / \mathrm{mmr} .2017 .8292$

\begin{abstract}
The present study aimed to investigate the effects of strontium ranelate (SR), an anti-osteoporotic drug, on osteolysis in an experimental mouse model of aseptic loosening. A total of 45 female C57BL/6J mice each received implantation of one titanium alloy pin into the tibia, followed by intraarticular injection of titanium particles. One week following surgery, mice were randomly divided into three groups: Control group (no additional treatment), SR625 group (treated with SR at a dose of $625 \mathrm{mg} / \mathrm{kg} / \mathrm{day}$ ), and SR1800 group (treated with SR at a dose of $1,800 \mathrm{mg} / \mathrm{kg} /$ day). SR was administered via oral gavage once every day for 12 weeks. Micro-computed tomography scanning and hematoxylin/eosin staining were used to assess osteolysis around the prosthesis. Immunohistochemistry and reverse transcription-quantitative polymerase chain reaction analysis were used to measure the expression of receptor activator of nuclear factor $-\kappa \mathrm{B}$ ligand (RANKL) and osteoprotegerin (OPG). Compared with the control, the SR625 and SR1800 groups exhibited a significantly increased pulling force of the titanium alloy pin. Bone volume and the bone surface/volume ratio in the periprosthetic tissue were significantly increased in the SR-treated groups. Significant differences were
\end{abstract}

Correspondence to: Dr Qunhua Jin, Department of Orthopedic Surgery, General Hospital of Ningxia Medical University, 804 South Shengli Street, Yinchuan, Ningxia 750004, P.R. China

E-mail: jinqunhua@sina.com

Abbreviations: $\mathrm{BV}$, bone volume; BV/TV, bone volume fraction; OPG, osteoprotegerin; RANKL, receptor activator of nuclear factor- $\kappa \mathrm{B}$ ligand; SR, strontium ranelate; Tb.N, trabecular number; Tb.Th, trabecular thickness; Ti, titanium; $\mu \mathrm{CT}$, micro-computed tomography

Key words: aseptic loosening, titanium particles, strontium ranelate, receptor activator of nuclear factor- $\kappa \mathrm{B}$ ligand, osteoprotegerin observed between the SR1800 group and control group with respect to trabecular thickness and trabecular number. Mechanistically, SR downregulated the expression of RANKL and upregulated the expression of OPG in the periprosthetic tissue. In addition, SR was observed to inhibit wear particle-associated osteolysis in a dose-dependent manner. In conclusion, the present data illustrated that SR inhibited titanium particle-induced osteolysis in vivo.

\section{Introduction}

Aseptic loosening induced by wear particles has become one of the most critical contributors to arthroplasty failure (1). Wear particles are debris from joint replacement implants that are able to induce inflammation and bone resorption at the interface between the prosthesis and its adjoining bone $(2,3)$. Various measures have been used for the prevention and treatment of aseptic loosening. Strontium ranelate (SR) is an anti-osteoporotic drug, and has the potential to reduce the risk of spinal and hip fractures in postmenopausal women (4). SR is able to promote the proliferation of pre-osteoblasts, suppress the production and activity of osteoclasts, and increase osteoclast apoptosis $(5,6)$. Therefore, SR may be considered to be a potential treatment for aseptic loosening.

Receptor activator of nuclear factor- $\kappa \mathrm{B}$ ligand (RANKL) is secreted by osteoblasts and other cell types, including endothelial and active $\mathrm{T}$ cells $(7,8)$, and various inflammatory factors may stimulate its secretion (9-11). Upon binding to its membrane receptor (RANK), RANKL activates the nuclear factor $(\mathrm{NF})-\kappa \mathrm{B}$ signaling pathway and induces osteoclast differentiation, inhibits osteoclast apoptosis, and promotes osteoclast adhesion to the bone surface (12-14). Osteoprotegerin (OPG), a soluble competitive decoy receptor for RANK, is able to inhibit the NF- $\kappa$ B signaling pathway by interfering with the RANKL-RANK interaction $(11,15)$. OPG is secreted by a number of types of cells, including osteoblasts and mesenchymal stem cells (16). The interaction between OPG, RANKL and RANK, therefore, may serve an essential role in the regulation of bone metabolism (17-19). 
The present study aimed to investigate whether treatment with SR may inhibit aseptic loosening in an experimental mouse model that simulates artificial joint replacement, and reflects the interaction between wear particles and periprosthetic tissues (20), and to examine the potential biochemical mechanisms of action of SR.

\section{Materials and methods}

Preparation of wear particles. Unmixed titanium (Ti) particles (Zimmer Biomet, Warsaw, IN, USA) with an average size of $5 \mu \mathrm{m}$ were used. Prior to injection, the particles were rinsed in $70 \%$ ethanol for $48 \mathrm{~h}$ at room temperature, washed twice in PBS, and autoclaved at $180^{\circ} \mathrm{C}$ for $6 \mathrm{~h}$ to remove endotoxins. A commercial detection kit (E-Toxate; Sigma-Aldrich; Merck KGaA, Darmstadt, Germany) was used to test whether the treated wear debris contained endotoxins or not (21).

Animal experiment. A total of 45 10-week-old female C57BL/6J mice, each weighing $20 \pm 2 \mathrm{~g}$, were used in the present study. All mice were maintained with pressure-controlled ventilation at a constant temperature of $25^{\circ} \mathrm{C}$ and a relative humidity of $40-70 \%$ in a 12/12-h light/dark cycle, and were given lab chow and water ad libitum. The study protocol was approved by the Animal Ethics Committee of Ningxia Medical University (Yinchuan, China).

Animal experiments were performed as previously described (20). In all mice, an intraperitoneal injection of Nembutal ( $0.6 \%$ pentobarbital sodium) was given to induce general anesthesia, and the murine joint prosthesis model was established in the right lower extremities. Under sterile conditions, the tibial plateau was exposed through the medial parapatellar approach and one Ti pin was gently implanted into the proximal tibia, with the pin head being maintained in the same plane as the tibial plateau surface. The skin incision was washed with normal saline containing $100 \mathrm{U} / \mathrm{ml}$ penicillin and $100 \mathrm{mg} / \mathrm{ml}$ streptomycin, and each layer was separately closed with absorbable sutures (20). Prior to surgically inserting the Ti pin, the mouse tibial canal was injected with $10 \mu 1$ Ti suspension ( $4 \times 10^{4}$ particles of $\mathrm{Ti}$ in normal saline). Subsequently, every 2 weeks following surgery, $20 \mu \mathrm{l}$ Ti particles were injected into the joint capsule at week 2, 4, 6, 8, 10 and 12 . Mice were randomly divided into three groups for treatment with SR (S12911-2; PROTELOS ${ }^{\circledR}$; Servier, Stoke Poges, UK): Control group (joint prosthesis only), SR625 group (joint prosthesis and SR at a dose of $625 \mathrm{mg} / \mathrm{kg} / \mathrm{day}$ ), and SR1800 group (joint prosthesis and SR at a dose of $1,800 \mathrm{mg} / \mathrm{kg} / \mathrm{day}$ ). A total of 7 days post-surgery, mice were given SR via intragastric gavage. Animals were treated consecutively for 12 weeks and were sacrificed for histological analysis, immunohistochemical (IHC) analysis, Ti prosthesis steadiness examination and micro-computed tomography $(\mu \mathrm{CT})$ analysis.

Pullout test to assess Ti prosthesis steadiness. Following sacrifice, the tibia containing the Ti pin was removed (20). To expose the Ti pin head, all muscles and tissues around the bone were carefully removed. Each bone was fixed to a special clamp using dental cement, which was designed to align the long axis of the implant with the long axis of the HP-100 Control Electronic Universal Testing Machine (Yueqing
Zhejiang Instrument Scientific Co., Ltd). With the position of the mouse limb and the custom fixture controlled, the pin was pulled out of the tibial canal at a rate of $2.0 \mathrm{~mm} / \mathrm{min}$. Load data were recorded using automatic software (Edburg version 1.0; Yueqing Instrument Co., Ltd., Yueqing, China).

$\mu C T$ scans. Following removal of all soft tissues, tibias from four mice per group were fixed in $4 \%$ paraformaldehyde, at $4^{\circ} \mathrm{C}$ for 4 weeks. The fixed shin bones were scanned by $\mu \mathrm{CT}$ (SkyScan 1176; Bruker microCT, Kontich, Belgium) at a resolution of $9 \mu \mathrm{m}$. The $\mu \mathrm{CT}$ scans were acquired at a $900-\mathrm{ms}$ exposure time, $45-\mathrm{kW}$ voltage and 550-mA current. Automatic data analysis software (NRecon version 1.1.11; Bruker microCT) was used to reconstruct and acquire images based on the $\mu \mathrm{CT}$ analyses, and to determine the bone volume fraction (BV/TV), trabecular thickness (Tb.Th), trabecular number (Tb.N), bone volume (BV), and specific bone surface (BS/BV) of the shin bone surrounding the Ti pin. All horizontal cutting images were captured at two-fifths of the titanium nail, which was $2 \mathrm{~mm}$ from the lower edge of the top hat.

RNA isolation and reverse transcription-quantitative polymerase chain reaction $(R T-q P C R)$ analysis. Total RNA was extracted using TRIzol reagent (Invitrogen; Thermo Fisher Scientific, Inc., Waltham, MA, USA), according to the manufacturer's protocol. The 260/280 absorbance ratio was measured to verify RNA purity (NanoDrop; Thermo Fisher Scientific, Inc., Wilmington, DE, USA). First strand cDNA was synthesized with $1 \mu \mathrm{g}$ total RNA using the RevertAid First Strand cDNA Synthesis kit (Thermo Fisher Scientific, Inc.). A total of $2 \mu \mathrm{l}$ cDNA was used for each PCR mixture, containing SYBR ${ }^{\circledR}$ Premix Ex Taq $^{\mathrm{TM}}$ II (Tli RNaseH Plus; Takara Biotechnology Co., Ltd., Dalian, China). The reaction was subjected to a 40 -cycle amplification of $95^{\circ} \mathrm{C}$ for $30 \mathrm{sec}$, $95^{\circ} \mathrm{C}$ for $5 \mathrm{sec}$, and $60^{\circ} \mathrm{C}$ for $30 \mathrm{sec}$. The relative mRNA expression of selected genes was normalized to GAPDH and quantified using the $2^{-\Delta \Delta \mathrm{Cq}}$ method (22).

PCR primers used in the present study were: RANKL forward, 5'-TCCTGAGCCTCCATGAAAACG-3' and reverse, 5'-CCCACACTGTGTTGCAGTTC-3'; OPG forward, 5'-TGA AGTACCGGAGCTGTCCCC-3' and reverse, 5'-AGGCCA TATGTGCTGCAGTTCG-3'; and GAPDH forward, 5'-TTG TCAAGCTCATTGGGCTCATTT-3' and reverse, 5'-GCC ATGTAGGTCCACCCATG-3'.

Histopathological and IHC analysis. The tibia was fixed in $4 \%$ paraformaldehyde for $24 \mathrm{~h}$ at $4^{\circ} \mathrm{C}$, and immersed in EDTA solution for decalcification. The samples were dehydrated in a graded series of ethanol followed by xylene, prior to being embedded in paraffin at $60^{\circ} \mathrm{C}$. Sections $(5 \mu \mathrm{m})$ were cut perpendicular to the long axis of the tibia using an RM2235 Rotary Microtome-Basic Instrument (Leica Microsystems, Inc., Buffalo Grove, IL, USA). Sections were stained with hematoxylin and eosin $(\mathrm{H} \& \mathrm{E})$ for histomorphometric analysis: $0.5 \%$ water-soluble Eosin for $5 \mathrm{~min}$ at $23^{\circ} \mathrm{C}$ and Hematoxylin for $3 \mathrm{~min}$ at $23^{\circ} \mathrm{C}$. IHC staining for OPG and RANKL was implemented to assess the activity of osteoclastogenesis. EDTA was preheated to $60^{\circ} \mathrm{C}$ in a pressure cooker, then glass slides added to the autoclave for $2 \mathrm{~min}$, then allowed to cool for $20 \mathrm{~min}$. Following washing with PBS, the slides were incubated 
at $23^{\circ} \mathrm{C}$ for 10 min with $3 \%$ hydrogen peroxide, washed again with PBS and incubated with primary antibodies overnight at $4^{\circ} \mathrm{C}$. The primary antibodies used were: Rabbit polyclonal anti-OPG (cat. no. ab183910; 1:300; Abcam, Cambridge, UK); and rabbit polyclonal anti-RANKL (cat. no. ab9957; 1:300; Abcam). To exclude the possibility of nonspecific staining, negative controls were performed with PBS instead of primary antibodies. Then the slides were incubated with secondary antibodies (Enzyme-labeled goat anti-rabbit IgG polymer) part of the PV-9001 kit (Sino Biological, Beijing, China) at $23^{\circ} \mathrm{C}$ for $40 \mathrm{~min}$. Standardized IHC images were obtained with a microscopic imaging system (DM2000 LED; Leica Microsystems, Inc.), and positive expression was calculated using Image-Pro Plus version 6.0 software (Media Cybernetics Inc., Rockville, MD, USA).

Statistical analysis. Data are presented as the mean \pm standard deviation. Results were analyzed by one-way analysis of variance, among the three groups. The least significant difference post-hoc test was performed for the distinction of means between different groups. $\mathrm{P}<0.05$ was considered to indicate a statistically significant difference. SPSS 19.0 (IBM Corp., Armonk, NY, USA) was used for statistical analysis.

\section{Results}

Treatment with SR increases the pulling force of the Ti pin. The average pulling load was $1.21 \pm 0.61 \mathrm{~N}$ for the control group. Compared with the control group, significant increases in pulling force were detected in the SR625 group $(8.51 \pm 0.52 \mathrm{~N}$, $\mathrm{P}<0.01)$ and SR1800 group $(13.42 \pm 0.13 \mathrm{~N}, \mathrm{P}<0.01)$. A significant difference in pulling load was additionally observed between the SR625 and SR1800 groups ( $<<0.01$; Fig. 1).

Treatment with SR improves bone microstructure around the prosthesis. $\mu \mathrm{CT}$ scanning demonstrated differences in the bone microstructure among the three groups. Osteolysis around the control group pin was most marked (Fig. 2). Tb.Th, Tb.N, BS/BV, BV and BV/TV data were obtained from $\mu \mathrm{CT}$ analysis of the region of interest. Compared with the control group $(11.709 \pm 0.720 \%), \mathrm{BV} / \mathrm{TV}$ was significantly increased in the SR625 group $(13.390 \pm 0.628 \%, \mathrm{P}=0.048)$ and SR1800 group $(15.288 \pm 0.184 \%, \mathrm{P}=0.002)$ in a dose-dependent manner $(\mathrm{P}=0.031)$. Similarly, compared with the control group $\left(0.109 \pm 0.006 \mathrm{~mm}^{3}\right), \mathrm{BV}$ was significantly increased in the SR625 group $\left(0.125 \pm 0.004 \mathrm{~mm}^{3}, \mathrm{P}=0.048\right)$ and SR1800 group $\left(0.142 \pm 0.002 \mathrm{~mm}^{3}, \mathrm{P}=0.002\right)$ in a dose-dependent manner $(\mathrm{P}=0.031)$. Conversely, compared with the control group $(75.89 \pm 1.821 / \mathrm{mm})$, a significant decline in $\mathrm{BS} / \mathrm{BV}$ was observed in the SR625 group $(64.98 \pm 1.771 / \mathrm{mm}, \mathrm{P}=0.005)$ and SR1800 group $(60.36 \pm 1.061 / \mathrm{mm}, \mathrm{P}=0.001)$, although without a dose-dependent effect $(\mathrm{P}=0.123)$.

Additionally, compared with the control group $(0.041 \pm 0.001 \mathrm{~mm})$, Tb.Th was increased in the SR625 group $(0.043 \pm 0.001 \mathrm{~mm}, \mathrm{P}=0.175)$ and significantly increased in the SR1800 group $(0.047 \pm 0.001 \mathrm{~mm}, \mathrm{P}=0.011$; Fig. 3D). Furthermore, compared with the control group $(2.841 \pm 0.2181 / \mathrm{mm})$, Tb.N was increased in the SR625 group $(3.050 \pm 0.1571 / \mathrm{mm}, \mathrm{P}=0.154)$ and significantly increased in the SR1800 group (3.219 $\pm 0.0271 / \mathrm{mm}, \mathrm{P}=0.028$; Fig. 3E).

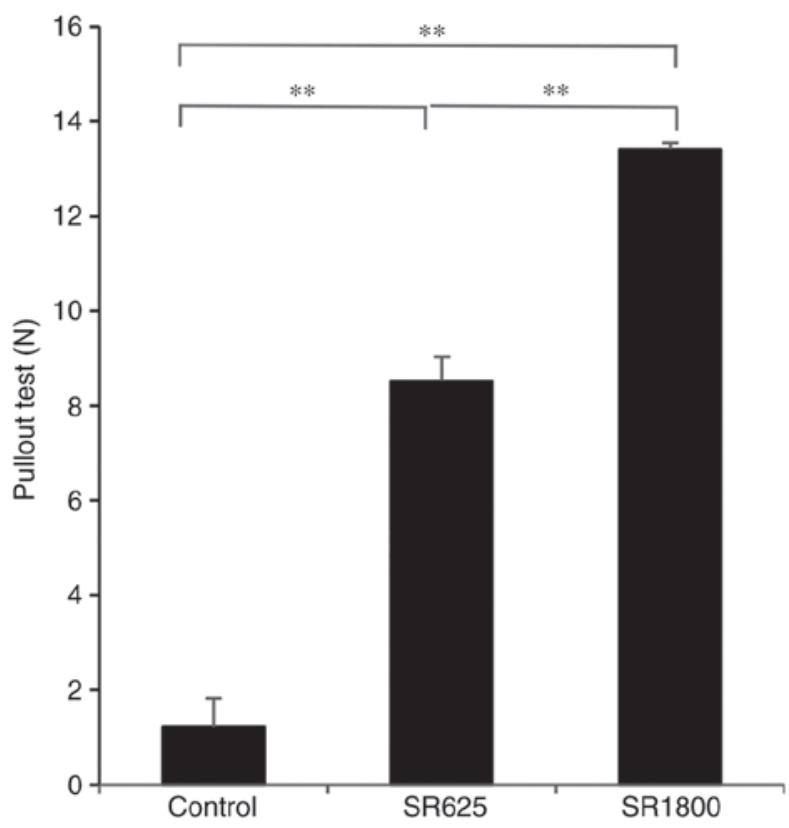

Figure 1. Pulling force required to remove the titanium pin implant in the three groups ${ }^{* *} \mathrm{P}<0.01$. $\mathrm{SR}$, strontium ranelate.
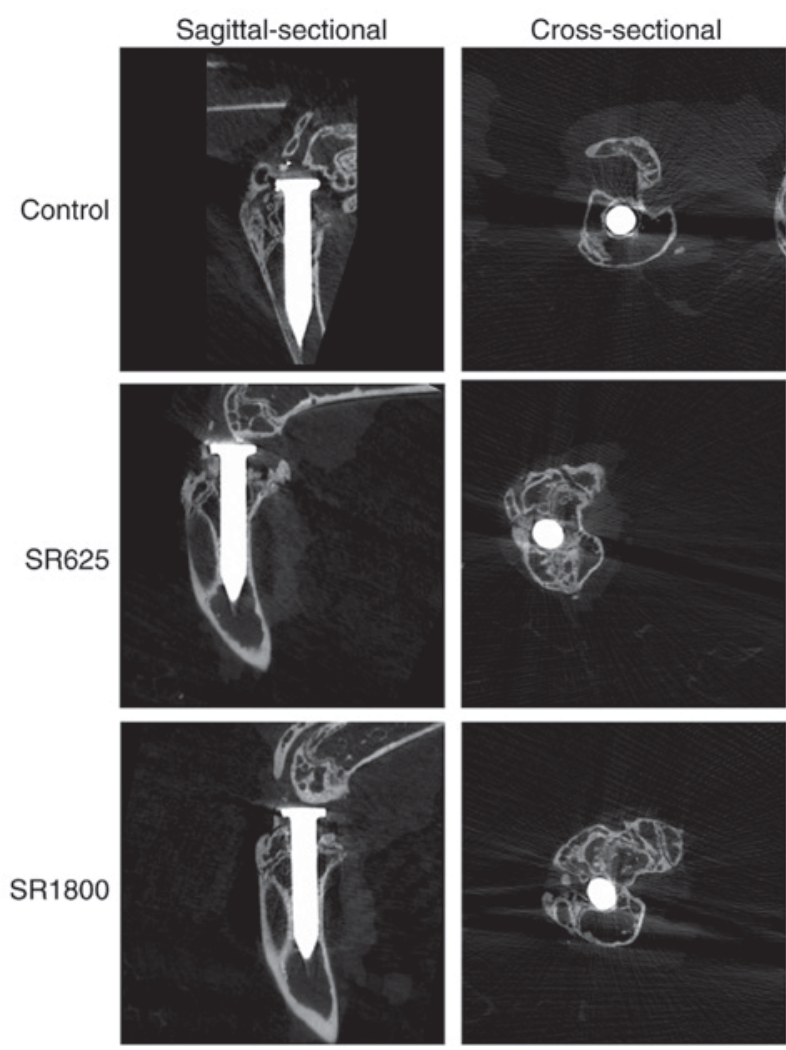

Figure 2. Sagittal-sectional and cross-sectional micro-computed tomography scans of titanium implants. SR, strontium ranelate.

Treatment with SR increases OPG expression and decreases RANKL expression in the periprosthetic tissue. H\&E staining indicated areas of bone resorption (Fig. 4). IHC was used to detect the expression of OPG and RANKL in all groups. Fig. 5 illustrates the expression of OPG and RANKL in the bone around prosthesis. Compared with the control group, 
A
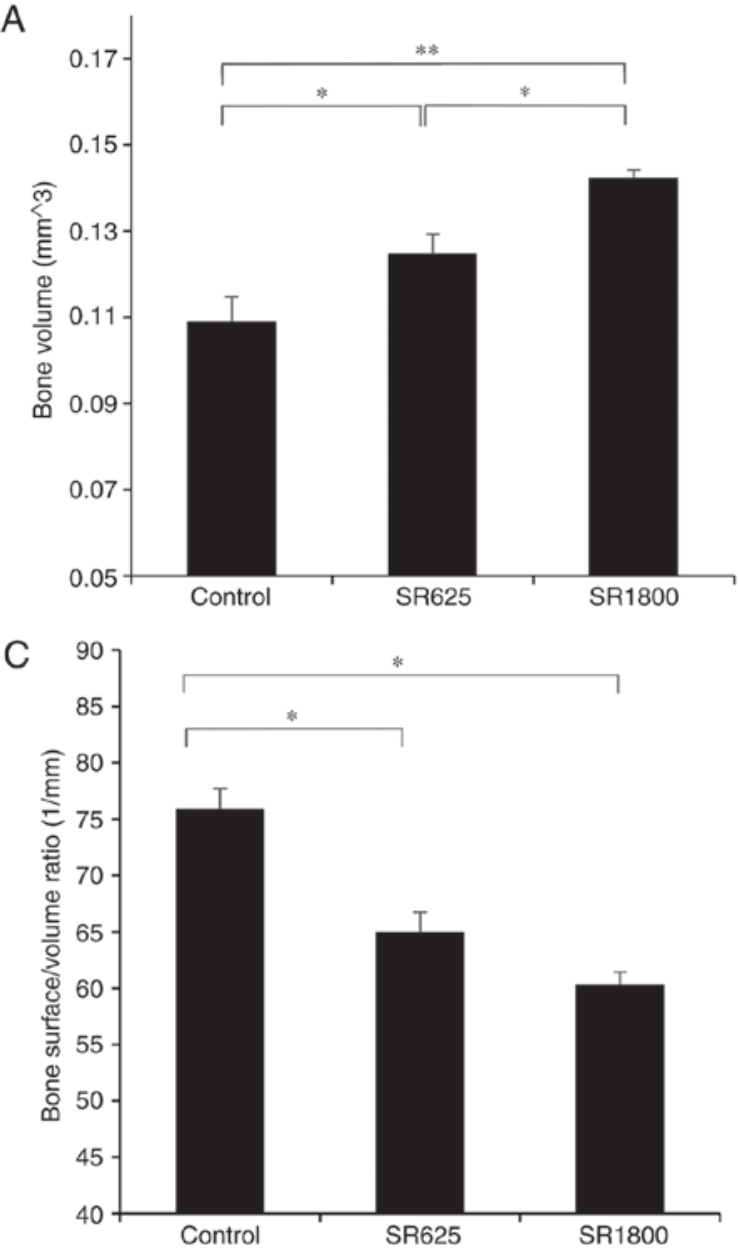

B
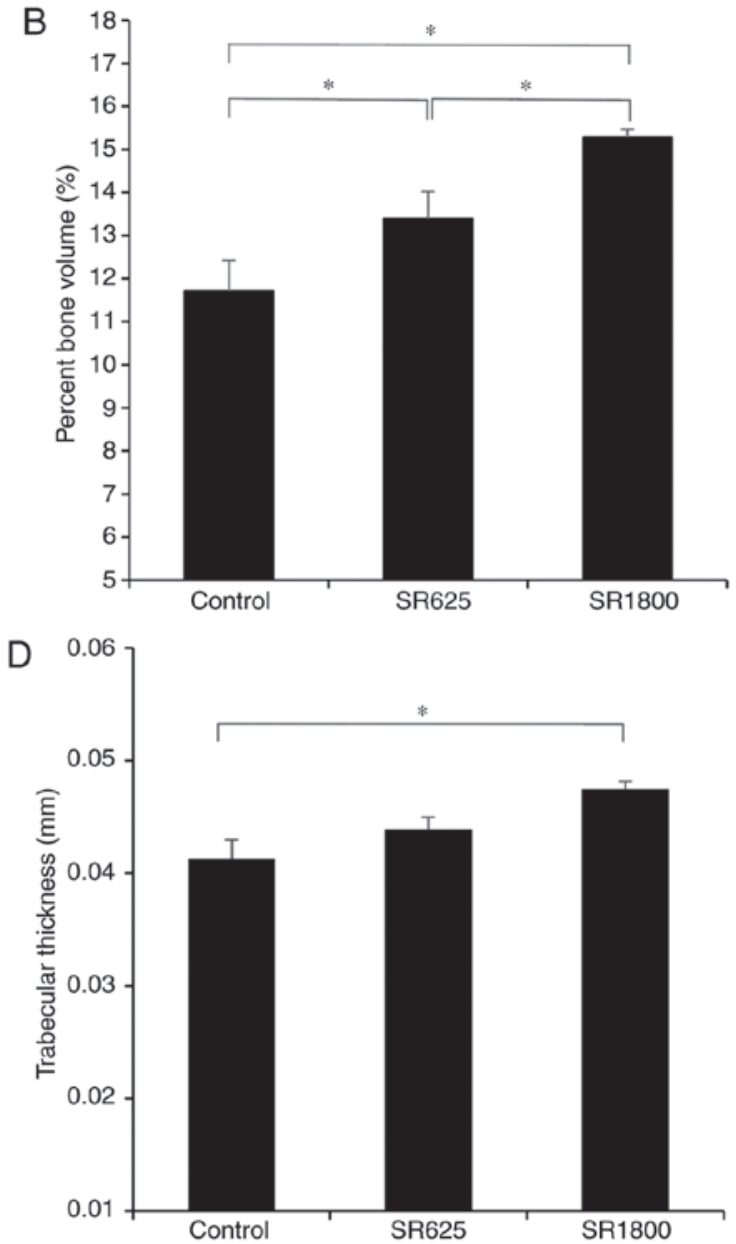

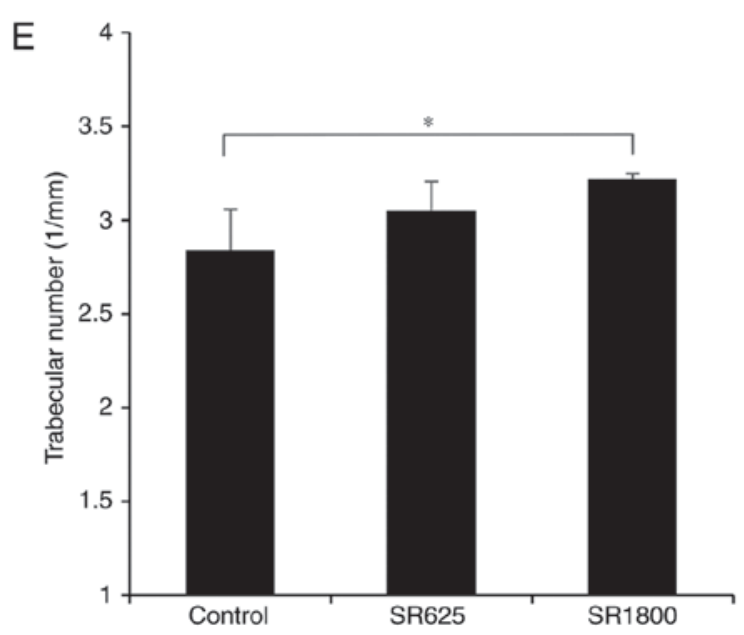

Figure 3. Micro-computed tomography analysis of bone microstructure. (A) Bone volume, (B) percentage bone volume, (C) bone surface density, (D) trabecular thickness and (E) trabecular number were measured. ${ }^{*} \mathrm{P}<0.05 ;{ }^{* *} \mathrm{P}<0.01$. SR, strontium ranelate.

the expression level of OPG was significantly increased in the SR1800 group $(0.422 \pm 0.010$ vs. $0.770 \pm 0.012$, respectively; $\mathrm{P}<0.001$; Fig. 6A) and the expression levels of RANKL were significantly decreased $(0.723 \pm 0.011$ vs. $0.221 \pm 0.009$, respectively; $\mathrm{P}<0.01$; Fig. $6 \mathrm{~B}$ ). Similarly, compared with the control group, expression levels of OPG were significantly increased in the SR625 group $(0.422 \pm 0.010$ vs. $0.590 \pm 0.007$, respectively; $\mathrm{P}<0.01$; Fig. $6 \mathrm{~A})$ and levels of RANKL were significantly decreased $(0.723 \pm 0.011$ vs. $0.400 \pm 0.018$, respectively; $\mathrm{P}<0.01$; Fig. 6B). In addition, the expression levels of
OPG and RANKL were significantly increased and decreased, respectively, to a greater extent in the SR1800 group compared with the SR625 group $(\mathrm{P}<0.01)$.

RT-qPCR analysis of OPG and RANKL in periprosthetic tissues demonstrated that, compared with the control group, the expression of OPG was significantly upregulated and the expression of RANKL was significantly decreased in response to treatment with SR $(\mathrm{P}<0.01)$. Additionally, this effect was significantly enhanced in the SR1800 group compared with the SR625 group $(\mathrm{P}<0.05$; Fig. 7$)$. 

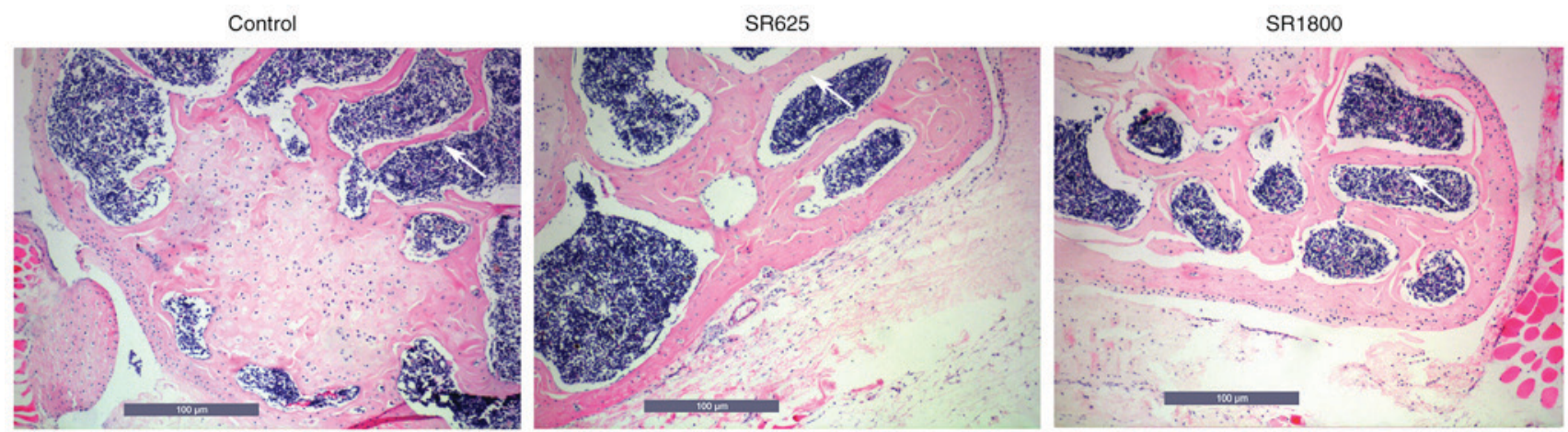

Figure 4. Histological assessment of periprosthetic tissue. Scale bar=100 $\mu \mathrm{m}$. SR, strontium ranelate.
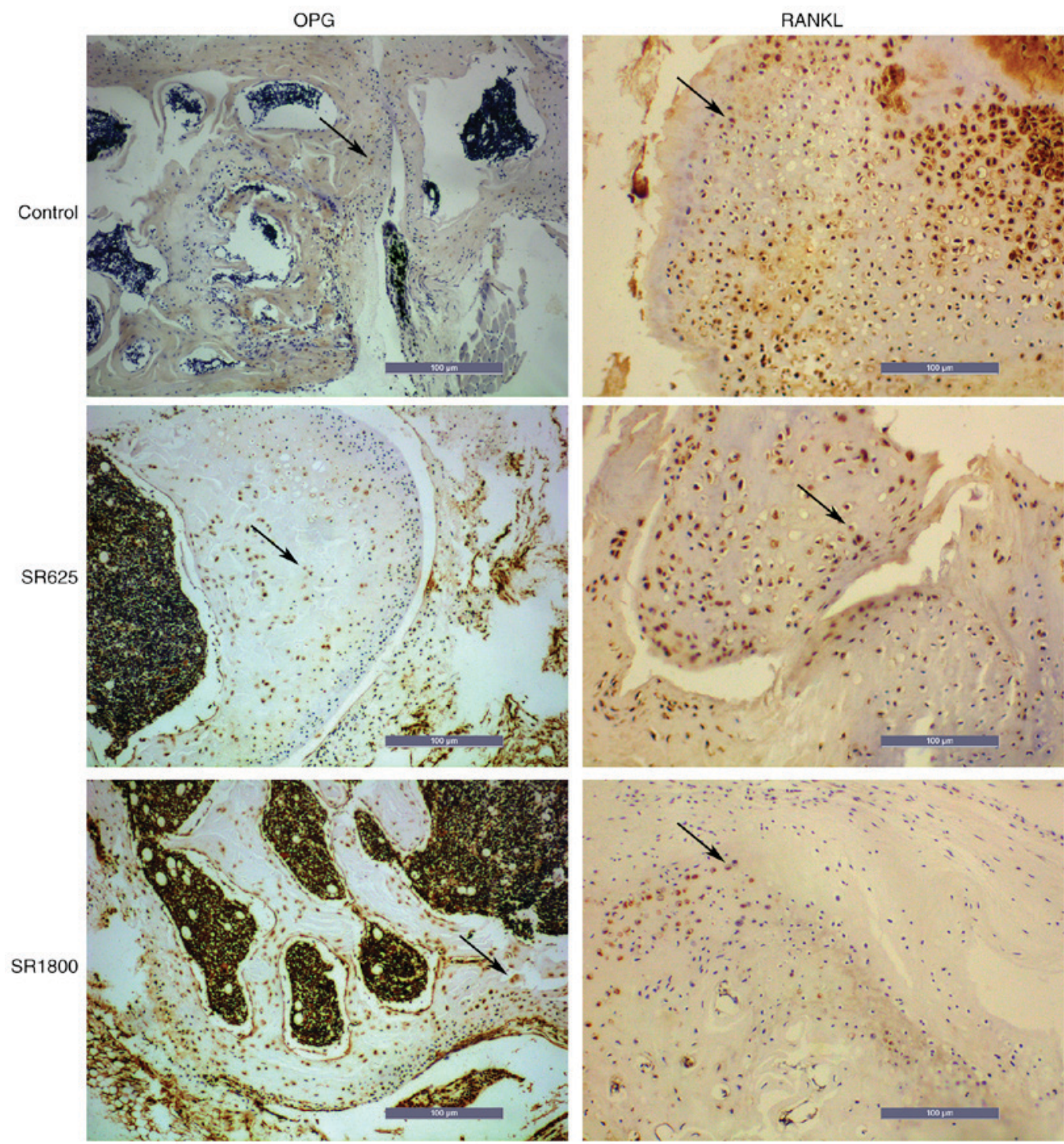

Figure 5. Immunohistochemical staining of OPG and RANKL. Scale bar=100 $\mu \mathrm{m}$. OPG, osteoprotegerin; RANKL, receptor activator of nuclear factor- $\mathrm{kB}$ ligand; SR, strontium ranelate.

\section{Discussion}

Total knee arthroplasty is an effective and reliable treatment for the terminal stage of knee arthritis. Following surgery, symptoms may effectively be controlled and join function restored (23-25). Aseptic loosening is one of the long-term complications of total joint replacement and is an important factor affecting the success rate of joint replacement. The pathogenesis of aseptic loosening is not clear, although previous studies indicated that an imbalance of osteogenesis and osteolysis around the prosthesis is the root cause $(5,6)$. 

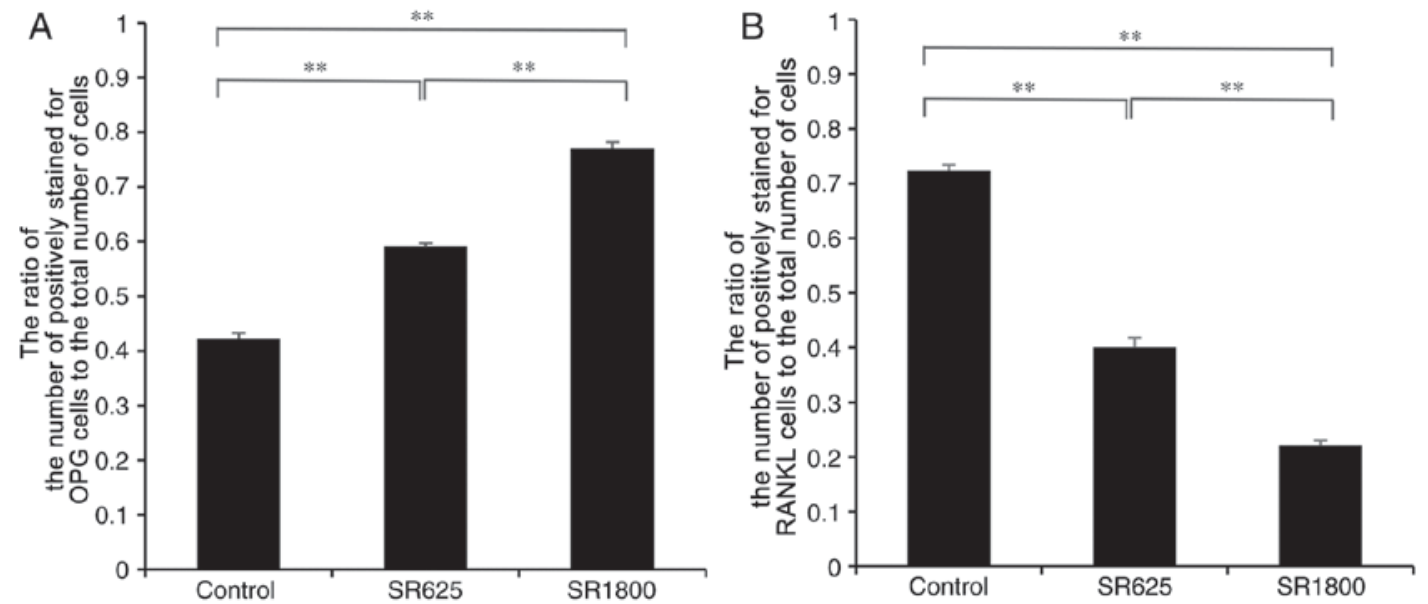

Figure 6. Immunohistochemical staining of OPG and RANKL. Semi-quantification of (A) OPG and (B) RANKL protein expression levels in periprothetic tissues. The ratios of the number of positively stained for OPG and RANKL cells to the total number of cells were plotted. ${ }^{* *} \mathrm{P}<0.01$. OPG, osteoprotegerin; RANKL, receptor activator of nuclear factor- $\mathrm{KB}$ ligand; SR, strontium ranelate.
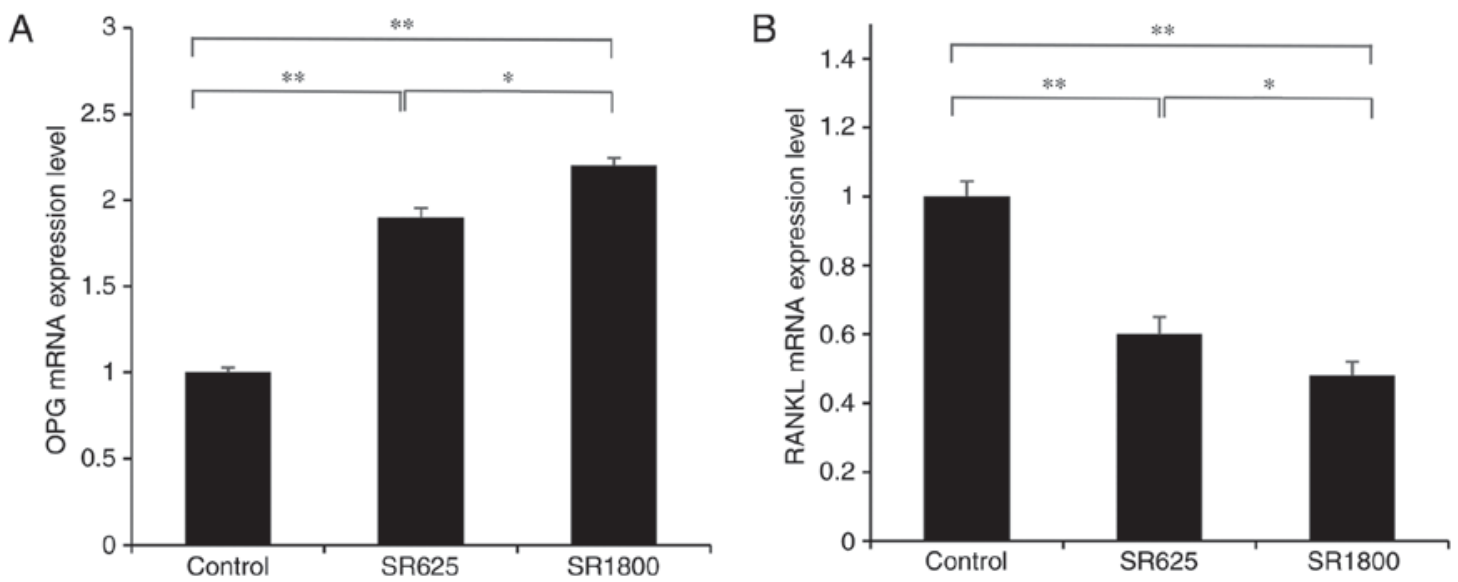

Figure 7. RT-qPCR analysis of OPG and RANKL. Relative mRNA expression levels of (A) OPG and (B) RANKL in periprosthetic tissue, as assessed by RT-qPCR analysis. " $\mathrm{P}<0.05 ;{ }^{* * *} \mathrm{P}<0.01$. OPG, osteoprotegerin; RANKL, receptor activator of nuclear factor- $\mathrm{kB}$ ligand; SR, strontium ranelate; RT-qPCR, reverse transcription-quantitative polymerase chain reaction.

In the present study, the pulling force to remove the $\mathrm{Ti}$ implant from the bone was enhanced following treatment with SR in a dose-dependent manner. This finding supports the idea that SR may be potentially effective against bone resorption. In accordance with the above, Liu et al (26) demonstrated that BV and BV/TV were significantly increased following treatment with SR. In another study by Lu et al (27), following treatment with $\mathrm{SR}, \mathrm{Tb}$.Th, bone density and BV/TV were significantly enhanced compared with the control. However, no significant differences in bone mineral density were noted between the treatment groups and the control. In the present study, BV and BV/TV around the periprosthetic tissue were significantly different between the control group and treatment groups. In addition, BV/TV was observed to be negatively associated with the dose of SR. SR dose did not significantly affect $\mathrm{BS} / \mathrm{BV}$ in the present study.

An aim of the present study was to determine the effect of $\mathrm{SR}$ on Tb.Th and Tb.N in mice with periprosthetic osteolysis. There were no statistically significant differences in Tb.Th or Tb.N between the SR625 group and the control group. However, significant differences in these parameters were observed between the SR1800 group and the control group. These results indicated that SR was able to increase BV, BS/BV (though not significantly), BV/TV, Tb.N and Tb.Th following aseptic loosening induced by wear particles, suggesting that SR may inhibit the development of aseptic loosening. $\mu \mathrm{CT}$ and $\mathrm{H} \& \mathrm{E}$ staining indicated that SR significantly reduced bone osteolysis compared with the control group. In this experiment, the bone formation rate was not measured, which is a limitation of the present study and requires investigation in the future.

In agreement with previous studies $(3,28)$, it was demonstrated that SR significantly decreased the level of RANKL and increased the secretion of OPG. The ratio of OPG to RANKL serves an important role in the balance of bone mass and bone metabolism (29-32). The homeostasis between bone formation and resorption is essential for the regulation of bone mass (33-36). Osteoclasts are responsible for dynamic bone resorption, and their differentiation and apoptosis are regulated by the ratio of OPG to RANKL (37,38). The binding of RANKL to RANK may be prevented by OPG, therefore the concentration of OPG and RANKL has an important influence on bone resorption $(39,40)$. The present study demonstrated that OPG and RANKL were significantly upregulated and downregulated, 
respectively, in the SR groups compared with the control group, at the mRNA and protein level. These findings support a key role of SR in inhibiting the differentiation of osteoclasts by regulating the ratio of RANKL/OPG in the aseptic loosening model.

It may be noted that previous studies have reported serious side effects with SR, such as Stevens-Johnson syndrome and toxic epidermal necrolysis $(41,42)$ although these were not observed in the present study. Topical application of SR is a promising method (43). Prostheses coated with SR may be able to inhibit aseptic loosening $(44,45)$.

In conclusion, SR inhibited wear particle-associated osteolysis effectively, in a dose-dependent manner. SR additionally downregulated the RANKL/OPG ratio, implying that SR may be a potential therapy for aseptic loosening.

\section{Acknowledgements}

The present study was supported by the National Natural Science Foundation of China (grant no. 81460333/H0606).

\section{References}

1. Landgraeber S, Putz S, Schlattjan M, Bechmann LP, Totsch M, Grabellus F, Hilken G, Jager M and Canbay A: Adiponectin attenuates osteolysis in aseptic loosening of total hip replacements. Acta Biomater 10: 384-393, 2014.

2. Yang H, Xu Y, Zhu M, Gu Y, Zhang W, Shao H, Wang Y, Ping Z, Hu X, Wang Land Geng D: Inhibition of titanium-particle-induced inflammatory osteolysis after local administration of dopamine and suppression of osteoclastogenesis via D2-like receptor signaling pathway. Biomaterials 80: 1-10, 2016.

3. Liu S, Virdi AS, Sena K and Sumner DR: Sclerostin antibody prevents particle-induced implant loosening by stimulating bone formation and inhibiting bone resorption in a rat model. Arthritis Rheum 64: 4012-4020, 2012.

4. Reginster JY, Brandi ML, Cannata-Andia J, Cooper C, Cortet B, Feron JM, Genant H, Palacios S, Ringe JD and Rizzoli R: The position of strontium ranelate in today's management of osteoporosis. Osteoporos Int 26: 1667-1671, 2015.

5. Karakan NC, Akpinar A, Göze F and Poyraz Ö: Investigating the effects of systemically administered strontium ranelate on alveolar bone loss histomorphometrically and histopathologically on experimental periodontitis in rats. J Periodontol 88: e24-e31, 2017.

6. Rybchyn MS, Slater M, Conigrave AD and Mason RS: An Akt-dependent increase in canonical Wnt signaling and a decrease in sclerostin protein levels are involved in strontium ranelate-induced osteogenic effects in human osteoblasts. J Biol Chem 286: 23771-23779, 2011.

7. Ferreira E, Bortolin RH, Freire-Neto FP, Souza KSC, Bezerra JF, Ururahy MAG, Ramos AMO, Himelfarb ST, Abreu BJ, Didone TVN, et al: Zinc supplementation reduces RANKL/OPG ratio and prevents bone architecture alterations in ovariectomized and type 1 diabetic rats. Nutr Res 40: 48-56, 2017.

8. Xiong J and O'Brien CA: Osteocyte RANKL: New insights into the control of bone remodeling. J Bone Miner Res 27: 499-505, 2012.

9. Wong BR, Josien R, Lee SY, Vologodskaia M, Steinman RM and Choi Y: The TRAF family of signal transducers mediates NF-kappaB activation by the trance TRANCE receptor. J Biol Chem 273: 28355-28359, 1998 .

10. Yasuda H, Shima N, Nakagawa N, Mochizuki SI, Yano K, Fujise N, Sato Y, Goto M, Yamaguchi K, Kuriyama M, et al: Identity of osteoclastogenesis inhibitory factor (OCIF) and osteoprotegerin (OPG): A mechanism by which OPG/OCIF inhibits osteoclastogenesis in vitro. Endocrinology 139: 1329-1337, 1998.

11. Wang H, Jia T, Zacharias N, Gong W, Du HX, Wooley PH and Yang SY: Combination gene therapy targeting on interleukin-1 $\beta$ and RANKL for wear debris-induced aseptic loosening. Gene Ther 20: 128-135, 2012.

12. Nakagawa N, Kinosaki M, Yamaguchi K, Shima N, Yasuda H, Yano $\mathrm{K}$, Morinaga T and Higashio K: RANK is the essential signaling receptor for osteoclast differentiation factor in osteoclastogenesis. Biochem Bioph Res Commun 253: 395-400, 1998.
13. Hofbauer LC and Schoppet M: Clinical implications of the osteoprotegerin/RANKL/RANK system for bone and vascular diseases. JAMA 292: 490-495, 2004.

14. Katsuyama H, Otsuki T, Tomita M, Fukunaga M, Fukunaga T, Suzuki N, Saijoh K, Fushimi S and Sunami S: Menaquinone-7 regulates the expressions of osteocalcin, OPG, RANKL and RANK in osteoblastic MC3T3E1 cells. Int J Mol Med 15: 231-236, 2005

15. Mamolini E, Cervellati C, Greco P, Carrieri A, Massari L, Crivellari I, Scapoli C and Bonaccorsi G: VDR, RANKL and OPG polymorphisms as possible predisposing cofactors of postmenopausal osteoporosis: Explorative study in Italian population. Gynecol Endocrinol 33: 937-941, 2017.

16. Chakravarti A, Marceau AA, Flamand L and Poubelle PE: Normal human primary CD4+ T lymphocytes synthesize and release functional osteoprotegerin in vitro. Lab Invest 88: 171-184, 2008.

17. Matsuzaki K, Udagawa N, Takahashi N, Yamaguchi K, Yasuda H, Shima N, Morinaga T, Toyama Y, Yabe Y, Higashio K and Suda T: Osteoclast differentiation factor (ODF) induces osteoclast-like cell formation in human peripheral blood mononuclear cell cultures. Biochem Bioph Res Commun 246: 199-204, 1998.

18. Theoleyre S, Wittrant Y, Tat SK, Fortun Y, Redini F and Heymann D: The molecular triad OPG/RANK/RANKL: Involvement in the orchestration of pathophysiological bone remodeling. Cytokine Growth Factor Rev 15: 457-475, 2004.

19. Wang Z, Ding L, Zhang S, Jiang T, Yang Y and Li R: Effects of icariin on the regulation of the OPG-RANKL-RANK system are mediated through the MAPK pathways in IL-1 $\beta$-stimulated human SW1353 chondrosarcoma cells. Int J Mol Med 34: 1720-1726, 2014.

20. Yang S, Yu H, Gong W, Wu B, Mayton L, Costello R and Wooley PH: Murine model of prosthesis failure for the long-term study of aseptic loosening. J Orthop Res 25: 603-611, 2007.

21. Guo H, Zhang J, Hao S and Jin Q: Adenovirus-mediated small interfering RNA targeting tumor necrosis factor- $\alpha$ inhibits titanium particle-induced osteoclastogenesis and bone resorption. Int J Mol Med 32: 296-306, 2013.

22. Livak KJ and Schmittgen TD: Analysis of relative gene expression data using real-time quantitative PCR and the 2(-Delta Delta C(T)) method. Methods 25: 402-408, 2001.

23. Bourne RB, Laskin RS and Guerin JS: Ten-year results of the first 100 genesis II total knee replacement procedures. Orthopedics 30 (8 Suppl): S83-S85, 2007.

24. Harato K, Bourne RB, Victor J, Snyder M, Hart J and Ries MD: Midterm comparison of posterior cruciate-retaining versus-substituting total knee arthroplasty using the genesis II prosthesis. A multicenter prospective randomized clinical trial. Knee 15: 217-221, 2008.

25. Meding JB, Galley MR and Ritter MA: High survival of uncemented proximally porous-coated titanium alloy femoral stems in osteoporotic bone. Clin Orthop Relat Res 468: 441-447, 2010.

26. Liu X, Zhu S, Cui J, Shao H, Zhang W, Yang H, Xu Y, Geng D and Yu L: Strontium ranelate inhibits titanium-particle-induced osteolysis by restraining inflammatory osteoclastogenesis in vivo. Acta Biomater 10: 4912-4918, 2014

27. Lu YC, Chang TK, Yeh ST, Fang HW, Lin CY, Hsu LI, Huang CH and Huang $\mathrm{CH}$ : The potential role of strontium ranelate in treating particle-induced osteolysis. Acta Biomater 20: 147-154, 2015.

28. Zhang T, Yu H, Gong W, Zhang L, Jia T, Wooley PH and Yang SY: The effect of osteoprotegerin gene modification on wear debris-induced osteolysis in a murine model of knee prosthesis failure. Biomaterials 30: 6102-6108, 2009.

29. Lacey DL, Timms E, Tan HL, Kelley MJ, Dunstan CR, Burgess T, Elliott R, Colombero A, Elliott G, Scully S, et al: Osteoprotegerin ligand is a cytokine that regulates osteoclast differentiation and activation. Cell 93: 165-176, 1998.

30. Park K, Ju WC, Yeo JH, Kim JY, Seo HS, Uchida Y and Cho Y: Increased OPG/RANKL ratio in the conditioned medium of soybean-treated osteoblasts suppresses RANKL-induced osteoclast differentiation. Int J Mol Med 33: 178-184, 2014.

31. Song R, Gu J, Liu X, Zhu J, Wang Q, Gao Q, Zhang J, Cheng L, Tong X, Qi X, et al: Inhibition of osteoclast bone resorption activity through osteoprotegerin-induced damage of the sealing zone. Int J Mol Med 34: 856-862, 2014.

32. Yasuda H, Shima N, Nakagawa N, Yamaguchi K, Kinosaki M, Mochizuki S, Tomoyasu A, Yano K, Goto M, Murakami A, et al: Osteoclast differentiation factor is a ligand for osteoprotegerin/osteoclastogenesis-inhibitory factor and is identical to TRANCE/RANKL. Proc Natl Acad Sci USA 95: 3597-3602, 1998. 
33. Atkins GJ, Kostakis P, Pan B, Farrugia A, Gronthos S, Evdokiou A, Harrison K, Findlay DM and Zannettino AC: RANKL expression is related to the differentiation state of human osteoblasts. J Bone Miner Res 18: 1088-1098, 2003.

34. Grimaud E, Soubigou L, Couillaud S, Coipeau P, Moreau A, Passuti N, Gouin F, Redini F and Heymann D: Receptor activator of nuclear factor kappaB ligand (RANKL)/osteoprotegerin $(\mathrm{OPG})$ ratio is increased in severe osteolysis. Am J Pathol 163: 2021-2031, 2003.

35. Holding CA, Findlay DM, Stamenkov R, Neale SD, Lucas H, Dharmapatni AS, Callary SA, Shrestha KR, Atkins GJ, Howie DW and Haynes DR: The correlation of RANK, RANKL and TNFalpha expression with bone loss volume and polyethylene wear debris around hip implants. Biomaterials 27: 5212-5219, 2006

36. Ndip A, Williams A, Jude EB, Serracino-Inglott F, Richardson S, Smyth JV, Boulton AJ and Alexander MY: The RANKL/RANK/OPG signaling pathway mediates medial arterial calcification in diabetic charcot neuroarthropathy. Diabetes 60: 2187-2196, 2011.

37. Peng X, Guo W, Ren T, Lou Z, Lu X, Zhang S, Lu Q and Sun Y: Differential expression of the RANKL/RANK/OPG system is associated with bone metastasis in human non-small cell lung cancer. PLoS One 8: e58361, 2013.

38. Balsa JA,Lafuente C, Gomez-Martin JM, Galindo J,Peromingo R, Garcia-Moreno F, Rodriguez-Velasco G, Martinez-Botas J, Gomez-Coronado D, Escobar-Morreale HF, et al: The role of serum osteoprotegerin and receptor-activator of nuclear factor- $\mathrm{kB}$ ligand in metabolic bone disease of women after obesity surgery. J Bone Miner Metab 34: 655-661, 2016.
39. Stuss M, Sewerynek E, Król I, Stępień-Kłos W and Jędrzejczyk S: Assessment of OPG, RANKL, bone turnover markers serum levels and BMD after treatment with strontium ranelate and ibandronate in patients with postmenopausal osteoporosis. Endokrynol Pol 67: 174-184, 2016.

40. Lee HY, Shen MX, Lim YL, Tay YK, Chan MM, Pang SM, Xiao ZW, Ang SB and Ren EC: Increased risk of strontium ranelate-related SJS/TEN is associated with HLA. Osteoporos Int 27: 2577-2583, 2016

41. Rossini M, Adami G, Adami S, Viapiana O and Gatti D: Safety issues and adverse reactions with osteoporosis management. Expert Opin Drug Saf 15: 321-332, 2016.

42. Guo X, Wei S, Lu M, Shao Z, Lu J, Xia L, Lin K and Zou D: Dose-dependent effects of strontium ranelate on ovariectomy rat bone marrow mesenchymal stem cells and human umbilical vein endothelial cells. Int J Biol Sci 12: 1511-1522, 2016.

43. Gu Z, Huang B, Li Y, Tian M, Li L and Yu X: Strontium-doped calcium polyphosphate/ultrahigh molecular weight polyethylene composites: A new class of artificial joint components with enhanced biological efficacy to aseptic loosening. Mater Sci Eng C Mater Biol Appl 61: 526-533, 2016.

44. Tian A, Zhai JJ, Peng Y, Zhang L, Teng MH, Liao J, Sun X and Liang X: Osteoblast response to titanium surfaces coated with strontium ranelate-loaded chitosan film. Int J Oral Maxillofac Implants 29: 1446-1453, 2014.

45. Newman SD, Lotfibakhshaiesh N, O'Donnell M, Walboomers XF, Horwood N, Jansen JA, Amis AA, Cobb JP and Stevens MM: Enhanced osseous implant fixation with strontium-substituted bioactive glass coating. Tissue Eng Part A 20: 1850-1857, 2014. 